\title{
Three non-invasive ventilation strategies for preterm infants with respiratory distress syndrome: a propensity score analysis
}

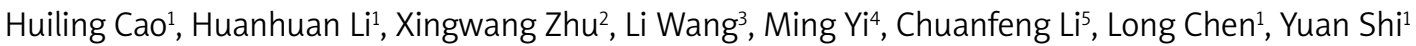

\begin{abstract}
'Department of Neonatology, Ministry of Education Key Laboratory of Child Development and Disorders; National Clinical Research Center for Child Health and Disorders; China International Science and Technology Cooperation base of Child development and Critical Disorders; Children's Hospital of Chongqing Medical University; Chongqing Key Laboratory of Pediatrics, Chongqing, China 2Department of Pediatrics, Jiulongpo People's Hospital, Chongqing, China ${ }^{3}$ Department of Pediatrics, Daping Hospital and Research Institute of Surgery, Army Military Medical University, Chongqing, China

${ }^{4}$ Department of Pediatrics, Chongqing Three Gorges Central Hospital, Chongqing, China ${ }^{5}$ Department of Pediatrics, Qujing Maternal and Child Health Hospital, Yunnan, China
\end{abstract}

Submitted: 26 November 2019

Accepted: 15 February 2020

Arch Med Sci 2020; 16 (6): 1319-1326

DOI: https://doi.org/10.5114/aoms.2020.93541

Copyright @ 2020 Termedia \& Banach

\section{Abstract}

Introduction: The present study was designed and conducted to compare the efficacy between nasal continuous positive airway pressure (NCPAP), nasal intermittent positive-pressure ventilation (NIPPV), and noninvasive high-frequency oscillatory ventilation (NHFOV) as the primary noninvasive ventilation in preterm infants with respiratory distress syndrome (RDS).

Material and methods: This multicenter retrospective cohort study was performed using data from four tertiary neonatal intensive care units (NICUs) in China between 2016 and 2018. 512 preterm infants with RDS who received early non-invasive ventilation (NIV) were analyzed. Propensity score analysis with 1 : 1 matching was performed with the nearest neighbor matching method using calipers of width equal to 0.1 of the standard deviation of the logit of the propensity score. The primary outcome was the need for intubation and invasive mechanical ventilation (IMV) within the first 7 days after birth. Secondary outcomes were days of hospitalization, predischarge mortality, rate of retinopathy of prematurity $(\mathrm{ROP})>$ stage II, rate of bronchopulmonary dysplasia (BPD) at 36 weeks post-menstrual age, rate of air leaks, rate of intraventricular hemorrhage (IVH) $\geq$ grade 3 , and rate of necrotizing enterocolitis (NEC) $\geq$ stage II.

Results: Propensity score matching identified 126 infants in each cohort (NHFOV vs. NIPPV), 96 infants in each cohort (NHFOV vs. NCPAP), 134 infants in each cohort (NIPPV vs. NCPAP) respectively. The need for IMV was significantly lower in the NHFOV as compared with NCPAP and NIPPV groups respectively (13/126 vs. $27 / 126, p=0.016$; $9 / 96$ vs. $20 / 96, p=0.027)$, while no difference was observed between NIPPV and NCPAP groups (25/134 vs. $25 / 134, p=0.805)$. However, the number of days of hospitalization in NIPPV was significantly lower than that of the NCPAP group $(24.8 \pm 14.6$ days vs. $33.2 \pm 20.2$ days $p=0.002$ ). In subgroup analyses, the need for IMV was significantly lower in the NHFOV group than in the NCPAP and NIPPV group (7: 79 vs. $15: 74 ; 95 \% \mathrm{Cl}: 1.00-6.836 ; p=0.044$ and $11: 102$ vs. $22: 98$; $95 \% \mathrm{Cl}: 1.092-5.251 ; p=0.026)$, and there was no difference between NIPPV and NCPAP in the preterm infants at $\leq 32$ weeks' gestational age. There were no significant differences among three groups ( $p>0.05$ respectively) regarding secondary outcomes.

\author{
Corresponding author: \\ Yuan Shi MD, PhD, MAPP \\ Department of Neonatology \\ Ministry of Education \\ Key Laboratory of \\ Child Development \\ and Disorders \\ China International Science \\ and Technology \\ Cooperation base \\ of Child Development \\ and Critical Disorders \\ Children's Hospital \\ of Chongqing Medical \\ University; Chongqing \\ Key Laboratory of Pediatrics, \\ Chongqing, China \\ Phone: 13508300283 \\ Fax: 63635567 \\ E-mail: shiyuan@hospital. \\ cqmu.edu.cn
}


Conclusions: In this multicenter retrospective cohort study, NHFOV significantly reduced the need for IMV within the first 7 days as compared to NCPAP and NIPPV in the treatment of preterm infants with RDS without increasing the incidence of adverse events. However, NIPPV was not found to be superior to NCPAP for decreasing the need for IMV in the treatment of preterm infants with RDS.

Key words: neonatal respiratory distress syndrome, continuous positive airway pressure, nasal intermittent positive-pressure ventilation, noninvasive high-frequency oscillatory ventilation.

\section{Introduction}

Invasive mechanical ventilation (IMV) improves survival for respiratory distress syndrome (RDS) in premature infants, but is associated with various complications including ventilator-associated lung injury, infection, and bronchopulmonary dysplasia (BPD) [1]. American Academy of Pediatrics and European Consensus Guidelines recommend non-invasive ventilation (NIV) in the treatment of RDS $[2,3]$. Nasal continuous positive airway pressure (NCPAP) is recommended as the optimal first mode of respiratory support; however, the failure rate of NCPAP and the need for intubation and IMV remain high, especially in extremely preterm infants $[4,5]$. Noninvasive intermittent positive airway pressure ventilation (NIPPV) superimposes an intermittent peak pressure on CPAP. NIPPV is gaining wider acceptance as a second-line NIV after failure of NCPAP [6]. The recent meta-analyses indicated that early NIPPV did appear to be superior to NCPAP for decreasing the need for intubation among preterm infants with RDS [7]. However, Kirpalani et al. failed to demonstrate that NIPPV improved the rate of survival without BPD at 36 weeks of post-menstrual age, as compared with NCPAP in a large multicenter trial [8]. Nasal high-frequency oscillatory ventilation (NHFOV) is an emerging NIV mode that applies an oscillatory pressure wave form on CPAP [9]. Retrospective studies have shown that NHFOV might be a promising NIV mode to decrease intubation in preterm infants with RDS $[10,11]$. Four small randomized trials have compared NHFOV with NCPAP for the initial management of infants with RDS, but the conclusions were not consistent [12-15]. Up to now, there has been only limited clinical evidence of superiority of NIPPV or NHFOV over NCPAP for the management of infants with RDS.

We conducted this multicenter retrospective study to compare the effectiveness of NCPAP/ NIPPV/NHFOV used as initial treatment for infants with RDS. A propensity score analysis was used to balance patient characteristics and reduce bias when performing a retrospective comparison of patients treated with these regimens.

\section{Material and methods}

\section{Study design}

This multicenter retrospective cohort study was performed using data from four tertiary neonatal intensive care units (NICUs) in China from January 2016 to December 2018. 512 preterm infants (gestational age of 26 weeks 0 day to 33 weeks 6 days) with RDS who received NHFOV or NIPPV or NCPAP after birth were analyzed. The exclusion criteria were: 1) intubated for resuscitation or for other reasons; 2) crossover among the three NIV strategies; 3) major congenital malformations or known complex congenital heart disease. Approval for the study and sharing data with the coordinating institution was granted by the Children's Hospital of Chongqing Medical University and registered at www.chictr.org.cn, No.: ChiCTR1900027079 (registration date, October 30, 2019).

\section{Standard for diagnosis of RDS}

The diagnosis of RDS was based on clinical manifestations and chest X-ray findings. The clinical signs and symptoms of RDS were respiratory distress, tachypnea, nasal flaring, groan, and cyanosis appearing within the first $24 \mathrm{~h}$ of life. The typical X-ray picture of RDS showed a grain shadow, air bronchogram or white lung.

\section{Noninvasive ventilation strategies}

The criteria for initiation of NIV: 1) Early prophylactic use in extremely premature infants with spontaneous breathing in the delivery room; 2) all babies at risk of RDS, such as those < 30 weeks' gestation who do not need intubation for stabilization; 3) when $\mathrm{FiO}_{2}>0.30$ by nasal catheter, mask, or hood for oxygen, $\mathrm{PaO}_{2}<50 \mathrm{~mm} \mathrm{Hg}$ or $\left.\mathrm{TcSO}_{2}<0.90 ; 4\right)$ apnea of prematurity.

In the delivery room, all preterm infants were supported with NCPAP (PEEP: $6-8 \mathrm{~cm} \mathrm{H}_{2} \mathrm{O}$ ). Infants were transferred to the NICU within $1 \mathrm{~h}$ after birth, and then began to receive three different NIV strategies (NCPAP: $n=197$; NIPPV: $n=163$, NHFOV: $n=152$ ) as initial treatment for RDS.

The NCPAP was provided by the continuous positive airway pressure system (Carefusion, USA). The respiratory parameter setting was a CPAP of 6-8 $\mathrm{cm} \mathrm{H}_{2} \mathrm{O}$.

The NIPPV was delivered by a time-cycled, pressure-limited and continuous-flow neonatal ventilator (Babylog 8000, Drager, Germany) in a non-synchronized mode. The respiratory parameter settings were: frequency of 10-30 breaths/min, peak inspiratory pressure (PIP) of $15-25 \mathrm{~cm} \mathrm{H}_{2} \mathrm{O}$, 
and positive end expiratory pressure (PEEP) of 4-6 $\mathrm{cm} \mathrm{H}$ O.

The NHFOV was administered using two different high-frequency ventilators via binasal prongs. Two sites used the Babylog 8000 (Drager, Germany), the other two sites used the SLE 5000 (UK) to deliver NHFOV. The respiratory parameter settings were: mean airway pressure of $6-10 \mathrm{H}_{2} \mathrm{O}$, frequency of $10 \mathrm{~Hz}$, inspiratory time of $50 \%$ (1:1), and oscillation amplitude of $20-35 \mathrm{~cm} \mathrm{H}_{2} \mathrm{O}$.

In all three modes, the lowest $\mathrm{FiO}_{2}$ was adjusted in order to maintain a $\mathrm{SaO}_{2}$ of $90-94 \%$.

\section{Surfactant administration}

The indication of surfactant administration was similar in the four NICUs. Surfactant (Curosurf; $200 \mathrm{mg} / \mathrm{kg}$ ) was administered in the case of increased $\mathrm{FiO}_{2}$ greater than 0.40 to a target $\mathrm{SpO}_{2}$ of $90-94 \%$, by the INSURE (intubation, surfactant, extubation) technique [2].

\section{Caffeine treatment}

Caffeine (Caffeine Citrate Injection, Chiesi Pharmaceuticals, Parma, Italy) was administered when infants presented with any apnea. The initial loading dose was $20 \mathrm{mg} / \mathrm{kg}$, and the maintenance dose was $5 \mathrm{mg} / \mathrm{kg} /$ day.

\section{Outcomes}

The primary outcome was the need for intubation and IMV within the first 7 days of life in preterm infants after birth. The criteria for intubation and mechanical ventilation were as follows $[16,17]:$ (1) severe respiratory acidosis $\left(\mathrm{P}_{\mathrm{a}} \mathrm{CO}_{2}\right.$ $>65 \mathrm{~mm} \mathrm{Hg}$ with $\mathrm{pH}$ < 7.20); (2) severe apnea and bradycardia (defined as recurrent apnea with $>3$ episodes/h associated with heart rate $<100 / \mathrm{min}$, a single episode of apnea that requires mask ventilation); (3) hypoxia $\left(\mathrm{FiO}_{2}>0.5\right.$ with $\mathrm{PaO}_{2}<50 \mathrm{~mm} \mathrm{Hg}$ ) for at least $2 \mathrm{~h}$; (4) other specific circumstances based on the medical team's discretion at each site.

Secondary outcomes included days of hospitalization, predischarge mortality, rate of retinopathy of prematurity (ROP) > stage II, bronchopulmonary dysplasia (BPD) [18], air leaks, intraventricular hemorrhage $(\mathrm{IVH}) \geq$ grade 3 , and necrotizing enterocolitis (NEC) $\geq$ stage II. IVH classification was according to Papile et al. [19] and for NEC, Bell staging was used [20].

\section{Sample size calculation}

According to a retrospective study [21], the risk of failure while receiving initial NCPAP without INSURE in infants born between 25 and 32 weeks was $25 \%$. We assumed a reduction of $15 \%$ in in the primary outcome with NHFOV/NIPPV as compared with NCPAP. Considering an $\alpha$ error of 0.05 and a power of $80 \%, 96$ neonates would be needed at least in each group.

\section{Statistical analysis}

Logistic regression was used for propensity score calculation from baseline patient characteristics including gestational age, gender, birth weight, multiple pregnancy, cesarean delivery, Apgar score at $5 \mathrm{~min}$, corticosteroid, premature rupture of membrane, caffeine treatment, surfactant treatment and diabetes. Propensity score analysis with $1: 1$ matching was performed with the nearest neighbor matching method using calipers of width equal to 0.1 of the standard deviation of the logit of the propensity score. Multiple imputations were performed because the exclusion of patients with at least 1 missing variable may cause bias. If continuous data were normally distributed, differences among groups defined by exposure to different ventilations were examined using Student's $t$ test. If not, the nonparametric $H$ test was used for comparison of the three groups. The $\chi^{2}$ test and Fisher's exact test were used to analyze categorical variables. Statistical significance was considered if the $p$-value was $<0.05$. All statistical data analyses were performed using SPSS statistical software (version 22.0).

\section{Results}

Five hundred and twelve preterm infants with RDS who received NIV treatment were included. They were divided into three groups based on the initial NIV mode (197 in NCPAP group, 163 in NIPPV group and 152 in NHFOV group). Baseline patient characteristics before propensity score matching are described in Table I. Several differences were found. In order to avoid differences and deviations between retrospective study groups, we used propensity score matching. Propensity score matching identified 126 infants in each cohort (NHFOV vs NIPPV), 96 infants in each cohort (NHFOV vs. NCPAP), and 134 infants in each cohort (NIPPV vs. NCPAP) respectively. The perinatal characteristics of the studied groups are reported in Table II and no significant differences $(p>0.05$ respectively) were found between the three studied groups. The baseline patient characteristics after propensity score matching are listed in Table II.

The need for IMV was significantly lower in the NHFOV than NCPAP and NIPPV groups (13/126 vs. $27 / 126, p=0.027 ; 9 / 96$ vs. 20/96, $p=0.016)$, while no difference was observed between NIPPV and NCPAP groups (25/134 vs. 25/134, $p=1.00$ ) (Table III). However, the number of days of hospitalization in NIPPV was significantly lower than that in 
Huiling Cao, Huanhuan Li, Xingwang Zhu, Li Wang, Ming Yi, Chuanfeng Li, Long Chen, Yuan Shi

Table I. Baseline patient characteristics before propensity score matching

\begin{tabular}{|c|c|c|c|c|c|c|}
\hline Parameter & $\operatorname{NHFOV}(n=152)$ & NIPPV $(n=163)$ & $\operatorname{NCPAP}(n=197)$ & $P_{1}$ & $P_{2}$ & $P_{3}$ \\
\hline GA & $30.63 \pm 1.725$ & $31 \pm 1.863$ & $30.97 \pm 1.818$ & 0.070 & 0.079 & 0.876 \\
\hline BW & $1563 \pm 369.623$ & $1628.39 \pm 396.624$ & $1588.26 \pm 363.945$ & 0.136 & 0.536 & 0.318 \\
\hline Gender (\%) & $90(59.2)$ & $105(64.4)$ & $112(56.9)$ & 0.342 & 0.696 & 0.144 \\
\hline Multiple birth (\%) & $36(23.7)$ & $36(22.1)$ & $68(34.5)$ & 0.736 & 0.028 & 0.01 \\
\hline Caesarean birth (\%) & $89(58.6)$ & $104(63.8)$ & $118(59.9)$ & 0.339 & 0.647 & 0.517 \\
\hline Antenatal corticosteroids (\%) & $105(69.1)$ & $71(43.6)$ & $74(37.6)$ & 0.00 & 0.00 & 0.248 \\
\hline Diabetes (\%) & $10(6.6)$ & $13(8.0)$ & $37(18.9)$ & 0.634 & 0.002 & 0.008 \\
\hline $\begin{array}{l}\text { Premature rupture of } \\
\text { membranes (\%) }\end{array}$ & $60(39.5)$ & 31 (19) & $7(3.6)$ & 0.00 & 0.00 & 0.00 \\
\hline Cholestasis of pregnancy (\%) & $4(2.6)$ & $4(2.5)$ & $9(4.6)$ & 0.920 & 0.430 & 0.369 \\
\hline Caffeine treatment (\%) & $99(65.1)$ & $88(54.0)$ & $143(72.6)$ & 0.032 & 0.07 & 0.001 \\
\hline PS treatment (\%) & $119(78.3)$ & $118(72.4)$ & $152(77.2)$ & 0.226 & 0.801 & 0.299 \\
\hline 5 Apgar score & $9(8.25-10)$ & $8(8-10)$ & $9(8-10)$ & 0.001 & 0.940 & 0.003 \\
\hline
\end{tabular}

NHFOV - noninvasive high-frequency oscillatory ventilation, NIPPV - nasal intermittent positive-pressure ventilation, NCPAP - nasal continuous positive airway pressure, $P S$ - pulmonary surfactant, GA - gestational age week, BW - birth weight. $P_{1}-p$-value of NHFOV vs. NIPPV, $P_{2}-p$-value of NHFOV vs. NCPAP, $P_{3}-p$-value of NIPPV vs. NCPAP.

Table II. Baseline patient characteristics after propensity score matching

\begin{tabular}{|c|c|c|c|c|c|c|c|c|c|}
\hline Parameter & $\begin{array}{l}\text { NHFOV } \\
(n=126)\end{array}$ & $\begin{array}{c}\text { NIPPV } \\
(n=126)\end{array}$ & $P_{1}$ & $\begin{array}{l}\text { NHFOV } \\
(n=96)\end{array}$ & $\begin{array}{l}\text { NCPAP } \\
(n=96)\end{array}$ & $P_{2}$ & $\begin{array}{c}\text { NIPPV } \\
(n=134)\end{array}$ & $\begin{array}{c}\text { NCPAP } \\
(n=134)\end{array}$ & $P_{3}$ \\
\hline $\mathrm{GA}$ & $\begin{array}{l}30.69 \\
\pm 1.76\end{array}$ & $\begin{array}{l}30.71 \\
\pm 1.82\end{array}$ & 0.944 & $\begin{array}{l}30.76 \\
\pm 1.72\end{array}$ & $\begin{array}{l}30.86 \\
\pm 1.81\end{array}$ & 0.683 & $\begin{array}{l}30.99 \\
\pm 1.92\end{array}$ & $\begin{array}{l}30.91 \\
\pm 1.85\end{array}$ & 0.683 \\
\hline BW & $\begin{array}{l}1567.26 \\
\pm 364.70\end{array}$ & $\begin{array}{l}1557.26 \\
\pm 364.70\end{array}$ & 0.823 & $\begin{array}{l}1564.17 \\
\pm 395.12\end{array}$ & $\begin{array}{l}1578.97 \\
\pm 362.54\end{array}$ & 0.787 & $\begin{array}{c}1611.63 \\
\pm 396.86\end{array}$ & $\begin{array}{l}1596.19 \\
\pm 372.50\end{array}$ & 0.787 \\
\hline Gender (\%) & 79 (62.7) & $81(64.3)$ & 0.794 & $57(59.4)$ & $59(61.5)$ & 0.768 & $85(63.4)$ & 79 (59.0) & 0.768 \\
\hline $\begin{array}{l}\text { Multiple birth } \\
\text { (\%) }\end{array}$ & $28(22.2)$ & $28(22.2)$ & 1 & $23(24.0)$ & $26(27.1)$ & 0.619 & $33(24.6)$ & $37(27.6)$ & 0.619 \\
\hline $\begin{array}{l}\text { Caesarean } \\
\text { birth (\%) }\end{array}$ & 79 (62.7) & $83(65.9)$ & 0.599 & $61(63.5)$ & $59(61.5)$ & 0.592 & $84(62.7)$ & $82(61.2)$ & 0.592 \\
\hline $\begin{array}{l}\text { Antenatal } \\
\text { corticoste- } \\
\text { roids (\%) }\end{array}$ & $82(65.1)$ & $70(55.6)$ & 0.122 & $59(61.5)$ & $47(49.0)$ & 0.082 & $52(38.8)$ & $49(36.6)$ & 0.082 \\
\hline Diabetes (\%) & $10(7.9)$ & $11(8.7)$ & 0.820 & $8(8.3)$ & $14(14.6)$ & 0.174 & $12(9.0)$ & $17(12.7)$ & 0.174 \\
\hline $\begin{array}{l}\text { Premature } \\
\text { rupture of } \\
\text { membranes (\%) }\end{array}$ & $40(31.7)$ & $31(24.6)$ & 0.208 & $5(5.2)$ & $7(7.3)$ & 0.551 & $12(9.0)$ & $7(5.2)$ & 0.551 \\
\hline $\begin{array}{l}\text { Cholestasis } \\
\text { of pregnancy } \\
(\%)\end{array}$ & $3(2.4)$ & $4(3.2)$ & 0.701 & $2(2.1)$ & $0(0.0)$ & 0.155 & $4(3.0)$ & $2(1.5)$ & 0.155 \\
\hline $\begin{array}{l}\text { Caffeine } \\
\text { treatment (\%) }\end{array}$ & $77(61.1)$ & $82(65.1)$ & 0.145 & $60(62.5)$ & 69 (71.9) & 0.100 & $77(57.5)$ & $88(65.7)$ & 0.100 \\
\hline $\begin{array}{l}\text { PS treatment } \\
(\%)\end{array}$ & $96(76.2)$ & $94(74.6)$ & 0.770 & $75(78.1)$ & $79(82.3)$ & 0.469 & 99 (73.9) & $\begin{array}{c}104 \\
(77.6)\end{array}$ & 0.469 \\
\hline 5 Apgar score & $9(8-10)$ & $9(8-10)$ & 0.467 & $9(8-10)$ & $9(8-10)$ & 0.775 & $8(8-10)$ & $9(8-10)$ & 0.091 \\
\hline
\end{tabular}

NHFOV - noninvasive high-frequency oscillatory ventilation, NIPPV - nasal intermittent positive-pressure ventilation, NCPAP - nasal continuous positive airway pressure, PS - pulmonary surfactant, GA - gestational age week, BW - birth weight. $P_{1}-p$-value of NHFOV vs. NIPPV, $P_{2}-p$-value of NHFOV vs. NCPAP, $P_{3}-p$-value of NIPPV VS. NCPAP. 
Table III. Primary outcome and secondary outcome of 3 cohorts

\begin{tabular}{|c|c|c|c|c|c|c|c|c|c|}
\hline $\begin{array}{l}\text { Param- } \\
\text { eter }\end{array}$ & NHFOV & NIPPV & $P_{1}$ & NHFOV & NCPAP & $P_{2}$ & NIPPV & NCPAP & $P_{3}$ \\
\hline IMV: & & & 0.016 & & & 0.027 & & & 1.00 \\
\hline Yes & $13(10.3)$ & $27(21.4)$ & & $9(9.4)$ & $20(20.8)$ & & 25 (18.9) & $25(18.7)$ & \\
\hline No & $113(89.7)$ & 99 (78.6) & & $87(90.6)$ & $76(79.2)$ & & 109 (81.1) & 109 (81.3) & \\
\hline NEC: & & & 0.076 & & & 0.733 & & & 0.473 \\
\hline Yes & $9(7.1)$ & $3(2.4)$ & & $4(4.2)$ & $5(5.2)$ & & $3(2.2)$ & $5(3.7)$ & \\
\hline No & $117(92.9)$ & $123(97.6)$ & & $92(95.8)$ & $91(94.8)$ & & $131(97.8)$ & $129(96.3)$ & \\
\hline ROP: & & & 0.424 & & & 0.551 & & & 0.475 \\
\hline Yes & $6(4.8)$ & $9(7.1)$ & & $5(5.2)$ & $7(7.3)$ & & $8(6.0)$ & $11(8.2)$ & \\
\hline No & $120(95.2)$ & $117(92.9)$ & & $91(94.8)$ & $89(92.7)$ & & $126(94.0)$ & $123(91.8)$ & \\
\hline PNX: & & & 0.134 & & & 1.00 & & & 1.00 \\
\hline Yes & $3(2.4)$ & $0(0.0)$ & & $1(1.0)$ & $1(1.0)$ & & 0 & 0 & \\
\hline No & $123(97.6)$ & $126(100)$ & & $95(99.0)$ & $95(99.0)$ & & 134 & 134 & \\
\hline BPD: & & & 0.183 & & & 0.488 & & & 0.112 \\
\hline Yes & $10(7.9)$ & $5(4.0)$ & & $9(9.4)$ & $12(12.5)$ & & $7(5.2)$ & $14(10.4)$ & \\
\hline No & $116(92.1)$ & $121(96)$ & & 87 (90.6) & $84(86.5)$ & & $127(94.8)$ & $120(87.3)$ & \\
\hline Death: & & & 0.151 & & & 0.470 & & & 0.156 \\
\hline Yes & $6(4.8)$ & $2(1.6)$ & & $5(5.2)$ & $3(3.1)$ & & $2(1.5)$ & $0(0)$ & \\
\hline No & $120(95.2)$ & $124(98.4)$ & & $91(94.8)$ & $93(96.9)$ & & $132(98.5)$ & $134(100)$ & \\
\hline HS & $31.29 \pm 16.34$ & $27.73 \pm 14.79$ & 0.339 & $30.69 \pm 16.92$ & $33.46 \pm 21.37$ & 0.140 & $24.80 \pm 14.61$ & $33.22 \pm 20.2$ & 0.002 \\
\hline
\end{tabular}

the NCPAP group $(24.8 \pm 14.6$ vs. $33.2 \pm 20.2$ days, $p=0.002$ ) (Table III). There was no significant difference among the three groups in any secondary outcomes ( $p>0.05$ respectively) (Table III).

In subgroup analyses, the need for IMV did not show significant differences between the NHFOV versus NCPAP cohort and NHFOV versus NIPPV cohort at 32 to $34+6$ weeks' gestational age (2 : 17 vs. $5: 22 ; 95 \% \mathrm{Cl}: 0.372-13.090 ; p=0.376$ and $2: 24$ vs. $5: 28 ; 95 \% \mathrm{Cl}: 0.419-13.636 ; p=0.316)$. However, in the preterm infants at $\leq 32$ weeks' gestational age, the need for IMV was significantly lower in the NHFOV group than in the NCPAP and NIPPV groups (7: 79 vs. 15 : $74 ; 95 \% \mathrm{Cl}: 1.00-$ $6.836 ; p=0.044$ and $11: 102$ vs. $22: 98 ; 95 \% \mathrm{Cl}$ : $1.092-5.251 ; p=0.026$ ), and there was no difference between NIPPV and NCPAP in the subgroup (Table IV).

\section{Discussion}

In this retrospective study, we performed propensity score matching to balance baseline patient characteristics, and demonstrated that NHFOV, applied as the initial NIV for RDS treatment of preterm infants, had a significantly lower failure rate than NIPPV and NCPAP after matching. However, we found no significant difference between NIPPV and NCPAP in the risk of failure.
In addition, there was no difference between the three groups in any of the secondary outcomes.

We have previously reported that NHFOV significantly decreased the need for IMV compared with NCPAP in preterm infants with moderate-severe RDS ( $n=81$, GA 28-34 weeks) [12]. Recently, Iranpour et al. also found that NHFOV significantly reduced the duration of non-invasive respiratory support and decreased the need for intubation compared with NCPAP in infants with RDS ( $n=68$, GA 30-36 weeks) [13]. Moreover, a recent meta-analysis of randomized controlled trials concluded that NHFOV significantly removes carbon dioxide and reduces the risk of intubation compared with NCPAP [22]. The results of this retrospective study are consistent and offer additional evidence to support previous observations that showed the benefit of NHFOV over NCPAP in preterm infants with RDS, with a significant reduction in the need for IMV. Conversely, the trial of Mukerji included 39 infants with a birth weight of less than $1250 \mathrm{~g}$ and randomly assigned to NHFOV or biphasic positive airway pressure if they failed on NCPAP and demonstrated that failure of NHFOV was lower with biphasic positive airway pressure (37.5\% vs. $65.2 \%, p=0.09)$, although not statistically significant [14]. Considering the small sample size of the study, their results seemed inconclusive. The study by Malakian et al. [15] ran- 
Table IV. Subgroup analysis of primary outcome in 3 cohorts

\begin{tabular}{|c|c|c|c|}
\hline Parameter & IMV & $32-34^{+6}$, No. (Total, \%) & $\leq 32$ weeks, No. (Total, \%) \\
\hline NHFOV & $13(10.3)$ & $2(24,8.3 \%)$ & $11(102,10.8 \%)$ \\
\hline NIPPV & $27(21.4)$ & $5(28,17.9 \%)$ & $22(98,22.4 \%)$ \\
\hline$P_{1}$ & 0.016 & 0.316 & 0.026 \\
\hline OR & 2.371 & 2.391 & 2.395 \\
\hline $95 \% \mathrm{Cl}$ & $1.160-4.844$ & $0.419-13.636$ & $1.092-5.251$ \\
\hline NHFOV & $9(9.4)$ & $2(17,11.8 \%)$ & $7(79,8.9 \%)$ \\
\hline NCPAP & $20(20.8)$ & $5(22,22.7 \%)$ & $15(74,20.3 \%)$ \\
\hline$P_{2}$ & 0.027 & 0.376 & 0.044 \\
\hline OR & 2.544 & 2.206 & 2.615 \\
\hline $95 \% \mathrm{Cl}$ & $1.093-5.921$ & $0.372-13.090$ & $1.00-6.836$ \\
\hline NIPPV & $25(18.9)$ & $4(36,11.1 \%)$ & $21(98,21.4 \%)$ \\
\hline NCPAP & $25(18.7)$ & $8(33,24.2 \%)$ & $17(101,16.8 \%)$ \\
\hline$P_{3}$ & 1.00 & 0.151 & 0.409 \\
\hline OR & 1.00 & 2.560 & 0.742 \\
\hline $95 \% \mathrm{Cl}$ & $0.541-1.849$ & $0.691-9.481$ & $0.365-1.510$ \\
\hline
\end{tabular}

IMV - invasive mechanical ventilation, OR - odds ratio, 95\% Cl-95\% confidence interval. $P_{1}-p$-value of NHFOV vs. NIPPV, $P_{2}-p$-value of NHFOV vs. NCPAP, $P_{3}-p$-value of NIPPV vs. NCPAP.

domized preterm infants (GA 28-34 weeks; $n=$ 124) to NHFOV versus NCPAP and reported that NHFOV did not reduce the need for invasive mechanical ventilation during the first $72 \mathrm{~h}$, but the duration of noninvasive ventilation in the NHFOV group was significantly shorter. The difference between their outcomes and our findings may be due to the discrepancy in the different time-points of evaluation and analyses.

Contrary to our hypothesis, this study did not demonstrate a significant decrease in the primary outcome of the need for intubation and IMV in preterm infants receiving NIPPV for NIV support compared to those receiving NCPAP. Several randomized trials have compared NIPPV with NCPAP for the initial management of infants with RDS, showed discrepancies in obtained results [23-27]. Kugelman et al., Sai Sunil Kishore et al., and Shi et al. reported that early initiation of NIPPV may lead to a reduction in the need for intubation and IMV compared with NCPAP [23-25], while Chen et al. and Meneses et al. found that NIPPV had no advantage in reducing intubation compared with $\operatorname{NCPAP}[26,27]$. Recently, Bourque et al. performed a retrospective cohort study using NIPPV randomized control trial data of Kirpalani et al. They identified that failure rates were similar for NIPPV vs. NCPAP [28]. Our study also demonstrated no significant differences between NIPPV and NCPAP; however, the number of days of hospitalization in NIPPV was significantly lower than that in the
NCPAP group. We speculated that the main reason for the inconsistency among the aforementioned studies might be a wide range of set peak pressures (10-25 $\mathrm{cm} \mathrm{H} \mathrm{H}_{2} \mathrm{O}$ pressure), ventilator rates (10-60/min), variable inflation times (0.3-0.5 s), and synchronized or no synchronized breaths for use in NIPPV [29].

In subgroup analyses, we found that NHFOV significantly decreased the need for IMV compared with NCPAP and NIPPV in very preterm infants (gestational age < 32 weeks). Rüegger et al. [30] evaluated the effectiveness of NHFOV versus NCPAP for oxygen desaturation and bradycardia in very preterm infants. They also reported that NHFOV compared with NCPAP significantly reduced the frequency of desaturation and bradycardia. With a collapsing chest wall and poor diaphragmatic strength, smaller infants are more vulnerable to fail NCPAP due to closure of the glottis during the inspiratory phase. NHFOV does not induce glottal constrictor muscle activity, in contrast to NCPAP, obtaining a sufficient gas exchange and reducing the risk of apneas [30]. This may be an additional advantage of NHFOV relative to NCPAP in smaller preterm infants.

In the present study, we found no difference in any of the respiratory secondary outcomes among different NIV strategies, especially in the rate of BPD. Nevertheless, the following key points should be acknowledged: (1) The sample size was calculated based on the need for intubation rather than 
the rate of $B P D$, so it is possible that the sample size is too small to detect the difference of BPD among the different NIV. (2) The etiology of BPD is complex. Avoiding invasive ventilation does not mean reducing the incidence of BPD. Furthermore, the absence of differences in any other adverse events (i.e. IVH, NEC, pneumothorax, etc.) among different NIV strategies can offer additional evidence to support the similar safety of different NIV modes. According to the study of Handoka et al. [31], the failure of synchronous noninvasive intermittent positive pressure ventilation (SNIPPV) is related to the mean airway pressure (MAP). We did not compare the precise parameter of each group. This is the limitation of our study.

The limitations of the study are: 1 ) it was retrospective, and the retrospective nature of the study might inherently lead to the risk of missing data; 2) it was not randomized, and propensity score analysis could only balance known and selected variables; 3) there might remain a risk of bias in the choice of the mode of NIV. Actually, it was in some sense based on local practices and provided devices.

In conclusion, despite some limitations, this retrospective study demonstrates that NHFOV can reduce intubation and the need for IMV compared with NIPPV and NCPAP as an initial NIV for RDS treatment of preterm infants. To recommend the use of NHFOV as the primary mode of respiratory support for RDS in preterm infants, further multicenter randomized controlled trials are warranted.

\section{Acknowledgments}

Trial registry: No.: ChiCTR1900027079; URL:Www.chictr.org.cn

This work was funded by the "Guan'ai" preterm study Program of Renze Foundation of Beijing (K022).

Huiling Cao and Huanhuan Li equally contributted first authors of the paper.

\section{Conflict of interest}

The authors declare no conflict of interest.

\section{References}

1. Natarajan G, Pappas A, Shankaran S, et al. Outcomes of extremely low birth weight infants with bronchopulmonary dysplasia: impact of the physiologic definition. Early Hum Dev 2012; 88: 509-15.

2. Sweet DG, Carnielli V, Greisen G, et al. European consensus guidelines on the management of respiratory distress syndrome-2019 update. Neonatology 2019; 115: 432-50.

3. Cummings JJ, Polin RA, Committee on Fetus and Newborn, American Academy of Pediatrics. Noninvasive respiratory support. Pediatrics 2016; 137(1). doi: 10.1542/ peds.2015-3758.
4. Stefanescu BM, Murphy WP, Hansell BJ, Fuloria M, Morgan TM, Aschner JL. A randomized, controlled trial comparing two different continuous positive airway pressure systems for the successful extubation of extremely low birth weight infants. Pediatrics 2003; 112: 1031-8.

5. Barrington KJ, Bull D, Finer NN. Randomized trial of nasal synchronized intermittent mandatory ventilation compared with continuous positive airway pressure after extubation of very low birth weight infants. Pediatrics 2001; 107: 638-41

6. Roberts C, Davis PG, Owen LS. Neonatal non-invasive respiratory support: synchronized NIPPV, non-synchronized NIPPV or bi-level CPAP: what is the evidence in 2013? Neonatology 2013; 104: 203-9.

7. Lemyre B, Laughon M, Bose C, Davis PG. Early nasal intermittent positive pressure ventilation (NIPPV) versus early nasal continuous positive airway pressure (NCPAP) for preterm infants. Cochrane Database Syst Rev 2016; 12: CD005384.

8. Kirpalani H, Millar D, Lemyre B, Yoder BA, Chiu A, Roberts RS; NIPPV Study Group. A trial comparing noninvasive ventilation strategies in preterm infants. $\mathrm{N}$ Engl J Med 2013; 369: 611-20.

9. De Luca D, Dell'Orto V. Non-invasive high-frequency oscillatory ventilation in neonates: review of physiology, biology and clinical data. Arch Dis Child Fetal Neonatal 2016; 101: F565-70.

10. Mukerji A, Singh B, Helou SE, et al. Use of noninvasive high-frequency ventilation in the neonatal intensive care unit: a retrospective review. Am J Perinatol 2015; 30: 171-6.

11. Wang CH, Shi LP, Ma XL, Lin HJ, Xu YP, Du LZ. Use of noninvasive high-frequency oscillatory ventilation in very low birth weight infants. Zhonghua Er Ke Za Zhi 2017; 55: 177-81.

12. Zhu XW, Zhao JN, Tang SF, Yan J, Shi Y. Noninvasive high-frequency oscillatory ventilation versus nasal continuous positive airway pressure in preterm infants with moderate-severe respiratory distress syndrome: a preliminary report. Pediatr Pulmonol 2017; 52: 1038-42.

13. Iranpour R, Armanian AM, Abedi AR, Farajzadegan Z. Nasal high-frequency oscillatory ventilation (nHFOV) versus nasal continuous positive airway pressure (NCPAP) as an initial therapy for respiratory distress syndrome (RDS) in preterm and near-term infants. BMJ Paediatr Open 2019; 3: e000443.

14. Mukerji A, Sarmiento K, Lee B, Hassall K, Shah V. Non-invasive high frequency ventilation versus bi-phasic continuous positive airway pressure (BP-NCPAP) following CPAP failure in infants < 1250 g: a pilot randomized controlled trial. J Perinatol 2017; 37: 49-53.

15. Malakian A, Bashirnezhadkhabaz S, Aramesh MR, Dehdashtian M. Noninvasive high-frequency oscillatory ventilation versus nasal continuous positive airway pressure in preterm infants with respiratory distress syndrome: a randomized controlled trial. J Matern Fetal Neonatal Med 2019 Mar 8: 1-7. doi: 10.1080/14767058. 2018.1555810.

16. O'Brien K, Campbell C, Brown L, Wenger L, Shah V. Infant flow biphasic nasal continuous positive airway pressure (BP-NCPAP) vs. infant flow NCPAP for the facilitation of extubation in infants $\leq 1,250$ grams: a randomized controlled trial. BMC Pediatr 2012; 12: 43-51.

17. Chen L, Wang L, Ma J, Feng Z, Li J, Shi Y. Nasal high-frequency oscillatory ventilation in preterm infants with respiratory distress syndrome and ARDS after extuba- 
tion. A randomized controlled trial. Chest 2019; 155: $740-8$.

18. Jobe $A H$, Bancalari E. Bronchopulmonary dysplasia. Am J Respir Crit Care Med 2001; 163: 1723-9.

19. Papile LA, Burstein J, Burstein R, Kofffler H. Incidence and evolution of subependymal and intraventricular hemorrhage: a study of infants with birth weights less than 1,500 g. J Pediatr 1978; 92: 529-34.

20. Bell MJ, Ternberg JL, Feigin RD, et al. Neonatal necrotizing enterocolitis. Therapeutic decisions based upon clinical staging. Ann Surg 1978; 187: 1-7.

21. Dargaville PA, Gerber A, Johansson S, et al. Incidence and outcome of CPAP failure in preterm infants. Pediatrics 2016; 138: e20153985.

22. Li, J, Li X, Huang X, Zhang Z. Noninvasive high-frequency oscillatory ventilation as respiratory support in preterm infants: a meta-analysis of randomized controlled trials. Respir Res 2019; 20: 58.

23. Kugelman A, Feferkorn I, Riskin A, Chistyakov I, Kaufman B, Bader D. Nasal intermittent mandatory ventilation versus nasal continuous positive airway pressure for respiratory distress syndrome: a randomized, controlled, prospective study. J Pediatr 2007; 150: 521-6.

24. Sai Sunil Kishore M, Dutta S, Kumar P. Early nasal intermittent positive pressure ventilation versus continuous positive airway pressure for respiratory distress syndrome. Acta Paediatr 2009; 98: 1412-5.

25. Shi Y, Tang S, Zhao J, Shen J. A prospective, randomized, controlled study of NIPPV versus nCPAP in preterm and term infants with respiratory distress syndrome. Pediatr Pulmonol 2014; 49: 673-8.

26. Chen L, Wang L, Li J, Wang N, Shi Y. Noninvasive ventilation for preterm twin neonates with respiratory distress syndrome: a randomized controlled trial. Sci Rep 2015; 5: 14483.

27. Meneses J, Bhandari V, Alves JG, Herrmann D. Noninvasive ventilation for respiratory distress syndrome: a randomized controlled trial. Pediatrics 2011; 127: 300-7.

28. Bourque SL, Roberts RS, Wright CJ, et al. Nasal intermittent positive pressure ventilation versus nasal continuous positive airway pressure to prevent primary noninvasive ventilation failure in extremely low birthweight infants. J Pediatr 2020; 216: 218-21.e1.

29. Hadj-Ahmed MA, Samson N, Nadeau C, Boudaa N Praud JP. Laryngeal muscle activity during nasal highfrequency oscillatory ventilation in nonsedated newborn lambs. Neonatology 2015; 107: 199-205.

30. Ruegger CM, Lorenz L, Kamlin COF, et al. The effect of noninvasive high frequency oscillatory ventilation on desaturations and bradycardia in very preterm infants: a randomized crossover trial. J Pediatr 2018; 201: 269-73.

31. Handoka NM, Azzam M, Gobarah A. Predictors of early synchronized non-invasive ventilation failure for infants < 32 weeks of gestational age with respiratory distress syndrome. Arch Med Sci 2019; 15: 680-7. 